\title{
Exploring the efficiency of international tourism development in an emerging market
}

\author{
Meng-Chun Kao ${ }^{1}$, Che-Yang Lin ${ }^{1 \star}$, Mei-Chi Lai ${ }^{2}$ and Hao-Chen Huang ${ }^{3}$ \\ ${ }^{1}$ Department of Finance, Yuanpei University, No.306, Yuanpei Street, Hsinchu 30015, Taiwan, R.O.C. \\ ${ }^{2}$ Institute of Health Policy and Management, National Taiwan University, 6F., No.17, Syujhou Road, Taipei, 100, \\ Taiwan, R.O.C. \\ ${ }^{3}$ Graduate Institute of Finance, Economics, and Business Decision, National Kaohsiung University of Applied Sciences, \\ No. 415, Chien Kung Road, Kaohsiung, 807, Taiwan, R.O.C.
}

Accepted 23 June, 2011

\begin{abstract}
This work combines several analytical techniques, including data envelopment analysis (DEA) models and the canonical analysis model, in order to shed new light on the relative efficiency of international tourism development. This study analyzes the international tourism development in the 31 regions of China. For the analysis, we take the following inputs into consideration: the number of international travel agencies, employees of international travel agencies. As regards the outputs, we choose the number of international tourists, sales for international travel agencies, and foreign exchange earnings from travel. In the first stage, we use the canonical analysis model to investigate the correlations of related variables. In the second stage, we adopt DEA models, including Charnes, Cooper, and Rhodes (CCR), Banker, Charnes, and Cooper (BCC) and slacks-based measure (SBM), to analyze the relative efficiency of international tourism development. Finally, we provide some management suggestions for the development of international tourism industry in emerging China.
\end{abstract}

Key words: International tourism industry, canonical analysis, data envelopment analysis (DEA), slacks-based measure (SBM).

\section{INTRODUCTION}

Tourism is one of the fastest growing industries in many emerging countries such as China, Korea, and India. The Chinese government views the tourism industry as an engine for economic growth and has taken various measures to support it (Huang et al., 2007). Statistics and information from the Ministry of Tourism show that China has designated 99 cities as famous historical and cultural cities of national caliber, and has placed 750 cultural relics under key protection. There are also 119 national scenic and tourist resorts across the land. Nineteen Chinese scenes and sights have appeared on a UNESCO (United Nations Educational, Scientific and Cultural Organization) list of natural and cultural heritage sites. China's venerated history and splendid culture have resulted in a land that is pockmarked with cultural relics

\footnotetext{
${ }^{*}$ Corresponding author. E-mail: lincy@mail.ypu.edu.tw.
}

and treasures. Not only that the Chinese tourism industry is rich in resources, but it also has come a long way in terms of transportation, service, accommodation, catering and shopping facilities, and recreation. Due to the Chinese government's recently launched projects to support its tourism development, tourist facilities and service qualities are being constantly improved. Furthermore, international events such as the 2008 Beijing Olympic Games, the 2010 World Exposition, and the 2010 Asian Games are all closely related to the development of Chinese tourism industry. Therefore, the tourism industry and the number of international travel agencies have grown rapidly in China. By employing the data envelopment analysis (DEA) as the analytical tool, this work attempts to answer the following questions that which region performs better in terms of productivity of international tourism industry development and whether the host cities or regions of international sporting events perform better in terms of the relative efficiency of international 
tourism industry development.

In this work, we measure the relative efficiency of international tourism industry development in emerging China. The purposes of this work are to measure the productive efficiency of international travel agencies in an emerging country.

The methodology used to perform efficiency analysis of the international travel agencies is data envelopment analysis (DEA). DEA is a linear programming-based technique that converts multiple input and output measures into a single comprehensive measure of productivity efficiency (Charnes et al., 1978; Epstein and Henderson, 1989; Boussofiane et al., 1991; Mota et al., 1999; Medina-Borja and Triantis, 2007). Moreover, DEA is nonparametric, and therefore it does not require a prior assumption about the form of the production function to eliminate the possibility of the misspecification. Unlike other frontier approaches that define input-output relationships by estimating a true production frontier, DEA uses actual input-output data to construct a best practice frontier.

DEA has been widely applied to examine the performance and the efficiency of the tourism industry. A number of studies have considered the measurement of the hotel efficiency (Parkan, 1996; Hwang and Chang, 2003; Barros and Alves, 2004; Chiang et al., 2004; Barros, 2005; Wang et al., 2006; Yang and Lu, 2006; Haugland et al., 2007; Shang et al., 2008; and Hsieh et al., 2010). Some of the studies utilized the DEA procedure to evaluate managerial efficiency of hotels in Taiwan (Hwang and Chang 2003; Wang et al. 2006). Chiang et al. (2004) compared hotel performance under different structures of international tourist hotels in Taiwan. Barros (2005) estimated the efficiency of 43 Enatur hotels in Portugal by DEA. Shang et al. (2008) measured the ecommerce and hotel performance by applying DEA. Hsieh et al. (2010) also used DEA to measure the operational efficiency and effectiveness of international hotels in Taiwan.

According to the prior studies, the inputs are summarized including the number of employees, the number of guest rooms, food and beverage capacity and total cost as well as the outputs including the number of guests and various revenues such as room revenue, food and beverage revenue and other revenue. Moreover, Koksal and Aksu, (2007) considered three inputs, the number of staff, annual expenses and service capacity and one output variable, the number of customers to explore the efficiency of travel agencies in the Turkey. There are few studies to measure the efficiency of travel agencies that can be attributed to the lack of data. Furthermore, no studies on the relative efficiency of international tourism industry or international travel agencies in China have been done. In this work, we discuss the relative efficiency of inputs and outputs for international travel agencies to explore the performance of regional international tourism industry in China.

\section{METHODOLOGY AND DATA}

\section{Data envelopment analysis}

Farrell (1957) introduced a framework for efficiency evaluation and measurement, which was subsequently studied by Charnes et al. (1978), Banker et al. (1984) and others. Charnes et al. (1978) extended Farrell's model to multiple inputs and outputs. They utilized mathematical programming to develop an efficient frontier and to estimate the efficiency score. The CCR model, named after Charnes, Cooper, and Rhodes (1978), was limited to the following three restrictions: (1) constant returns to scales (CRS), (2) strong disposability of inputs and outputs, and (3) convexity of the set of feasible input-output combinations. For any special DMUs, the CCR model with constant return to scale can be formulated as follows to obtain a score of technical efficiency:

Maximize $w_{0}=\sum_{r} u_{r} y_{r j_{0}}$

s.t. $\sum_{i} v_{i} x_{i j_{0}}=1$,

$\sum_{r} u_{r} y_{r j}-\sum_{i} v_{i} x_{i j} \leq 0, j=1, \ldots, n$,

$u_{r} \geq \varepsilon, r=1, \ldots, s$,

$v_{i} \geq \varepsilon, i=1, \ldots, m$

where $m$ is the number of inputs, and $s$ is the number of outputs.

The BCC model, named after Banker, Charnes, and Cooper (1984), was developed by relaxing the CCR model or the constant returns to scale assumption on the envelopment surface. The constraint $\sum \lambda_{j}=1$ is added to the aforemrntioned mathematical formulation of the CCR model. We can achieve discrimination between departures due to pure technical inefficiency or to scale inefficiency.

Tone (2001) has proposed a slacks-based measure (SBM), which is non-radial and deals with input/ output slacks directly. The SBM returns an efficiency measure between 0 and 1 , and gives unity if and only if the DMU concerned is on the frontiers of the production possibility set without input/output slacks. In order to estimate the efficiency of a $\operatorname{DMU}\left(x_{0}, y_{0}\right)$, we formulate the following fractional program in $\lambda, s^{-}$, and $s^{+}$:

$\operatorname{Min} \rho=\frac{1-\frac{1}{m} \sum_{i=1}^{m} s_{i}^{-} / x_{i 0}}{1+\frac{1}{s} \sum_{r=1}^{s} s_{r}^{+} / y_{r 0}}$,

s.t. $x_{0}=X \lambda+s^{-}$,

$y_{0}=Y \lambda+s^{-}$,

$\lambda \geq 0, s^{-} \geq 0, s^{+} \geq 0$.

In this model, we assume that $X \geq 0$. If $x_{i 0}=0$, then we delete the term $s_{i}^{-} / s_{i 0}$ in the objective function. If $y_{r o} \leq 0$, then we replace it with a very small positive number so that the term $s_{r}^{+} / y_{r 0}$ plays the role of a penalty.

One of the DEA models, the bilateral comparison model, 
Table 1. Canonical structure matrix.

\begin{tabular}{lcc}
\hline Input canonical variable & Human resources $\left(\mathbf{W}_{1}\right)$ & Equipment resources $\left(\mathbf{W}_{\mathbf{2}}\right)$ \\
\hline Number of International travel agencies $\left(\mathrm{X}_{1}\right)$ & $-0.6055^{*}$ & $-0.7958^{\star}$ \\
Employees of international travel agencies $\left(\mathrm{X}_{2}\right)$ & $-0.9903^{*}$ & -0.1388 \\
& & \\
Output canonical variable & Service revenue $\left(\mathrm{V}_{\mathbf{1}}\right)$ & Reception services $\left(\mathrm{V}_{\mathbf{2}}\right)$ \\
Number of International Tourists $\left(\mathrm{Y}_{1}\right)$ & $-0.8457^{*}$ & $-0.5273^{\star}$ \\
Sales for international travel agencies $\left(\mathrm{Y}_{2}\right)$ & $-0.9039^{*}$ & -0.2457 \\
Foreign exchange earnings from travel $\left(\mathrm{Y}_{3}\right)$ & $-0.9090^{*}$ & -0.2004 \\
\hline
\end{tabular}

"*" Canonical loadings $>0.5$.

measured and compared efficiency between the host cities or regions of international sporting events (Group I) and other regions (Group II). The bilateral comparison model tested the null hypothesis that the efficiency of DMUs in the two studied groups belongs to the same statistical distribution obtained using nonparametric rank-sum statistics. The data format is the same as the CAT model, where the only level numbers assigned are I or II. This idea is formulated as follows for each DMU:

Min $\theta$

s.t. $\sum_{j \in I I} X_{j} \lambda_{j} \leq \theta X_{k}, k \in I$,

$\sum_{j \in I I} Y_{j} \lambda_{j} \geq \theta Y_{k}, k \in I$,

$\lambda_{j} \geq 0 \quad(\forall \mathrm{j} \in \mathrm{II})$

where $\theta$ denotes the efficiency score of international tourism industry

\section{Data selection and definitions of variables}

Mainland China has 31 regions ${ }^{1}$, including autonomous regions and municipalities. Consequently, thirty-one regions were subjected to empirical analysis in this study. Data from the China statistics database were used to determine the relative efficiency of these regions in China.

In this work, international travel agencies provided two inputs, which produced the outputs. Constructing the models allowed us to investigate the relative efficiency scores for international travel agencies. According to the prior studies, the inputs and outputs are selected as follows. The two inputs in the operational performance model are the number of international travel agencies $\left(x_{1}\right)$ and employees of international travel agencies $\left(x_{2}\right)$. Identifying the output of productive activities in general and of international travel agencies in particular presents difficulties for cost measurement and also production performance. The three outputs used here were the number of international tourists $\left(y_{1}\right)$, sales for international travel agencies $\left(y_{2}\right)$, and foreign exchange earnings from travel

\footnotetext{
${ }^{1}$ The DMUs contain China 31 regions including Beijing, Tianjing, Hebei, Shanxi, Inner Mogolia, Liaoning, Jilin, Heilongjiang, Shanghai, Jiangsu, Zhejiang, Anhui, Fujian, Jiangxi, Shandong, Henan, Hubei, Hunan, Guangdong, Guangxi, Hainan, Chongqing, Sichuan, Guizhou, Yunnan, Shaanxi, Gansu, Qinghai, Ningxja, Xinjiang, and Tibet.
}

$\left(y_{3}\right)$.These variables were defined as follows:

(1) Number of international travel agencies $\left(x_{1}\right)$ : Number of total international travel agencies.

(2) Employees of international travel agencies $\left(x_{2}\right)$ : The total number of employees who are full-time employees of international travel agencies.

(3) Number of international tourists (ten thousand) $\left(y_{1}\right)$ : Number of tourists served by the international tourist agencies.

(4) Sales for international travel agencies (million RMB) $\left(y_{2}\right)$ : Total sales revenue generating from international travel agencies.

(5) Foreign exchange earnings from travel (million RMB) $\left(y_{3}\right)$ : Total sales revenue generating from travel.

\section{RESULTS}

\section{Correlation analysis}

First, Pearson correlation test is utilized to measure the relationship between input and output variables. The result shows that the correlations of outputs and inputs are all positive and the correlation coefficients are all above 0.8 significantly at $1 \%$, indicating a highly relevant level. Furthermore, we used canonical correlation analysis (CCA) to reduce the dimension and investigate the correlations to quantify the associations between these two sets of variables, that is, the strength of the two sets of variables. The canonical correlation analysis revealed a significant correlation between the dynamics of the inputs and outputs variables. Canonical structure matrix generated the canonical variables, $\left(\mathrm{W}_{1}, \mathrm{~V}_{1}\right)$ and $\left(\mathrm{W}_{2}, \mathrm{~V}_{2}\right)$, as shown in Table 1. The results of canonical correlation analysis revealed a canonical first correlation value of $0.9332\left(\chi^{2}=71.774, p\right.$-value $\left.<0.01\right)$, and a second correlation value of $0.6759\left(\chi^{2}=16.484, p\right.$-value $\left.<0.01\right)$, as shown in Table 2. Figure 1 shows that the canonical first correlation revealed a significant correlation between human resources and service revenue $\left(\rho_{1}=0.9332\right)$, and a significant correlation between equipment resources and reception services $\left(p_{2}=0.6759\right)$. 
Table 2. Canonical correlation.

\begin{tabular}{ccccc}
\hline Canonical correlation & Canonical Coefficients $\left(\rho_{\mathrm{m}}\right)$ & df & $\chi^{2}$ & P-value \\
\hline$\rho_{1}$ & $0.9332^{\star * *}$ & 6 & 71.774 & 0.0000 \\
$\rho_{2}$ & $0.6759^{\star * *}$ & 2 & 16.484 & 0.0002 \\
\hline
\end{tabular}

* Significant at the 0.01 level, ${ }^{* *}$ significant at the 0.05 level, ${ }^{* * *}$ significant at the 0.1 level.

$\begin{array}{ccccccc}\text { Input } & \text { Canonical } & \text { Canonical } & \text { Canonical } & \text { Canonical } & \text { Canonical } & \text { Output } \\ \text { Variables }\left(\mathrm{X}_{\mathrm{L}}\right) & \text { Weights } & \text { Variables } & \text { Coefficients } & \text { Variables } & \text { Weights } & \text { Variables } \\ & (\mathrm{A}) & \left(\mathrm{W}_{\mathrm{m}}\right) & \left(\mathrm{N}_{\mathrm{m}}\right) & \left(\mathrm{V}_{\mathrm{m}}\right) & (\mathrm{B}) & \left(\mathrm{Y}_{\mathrm{p}}\right)\end{array}$

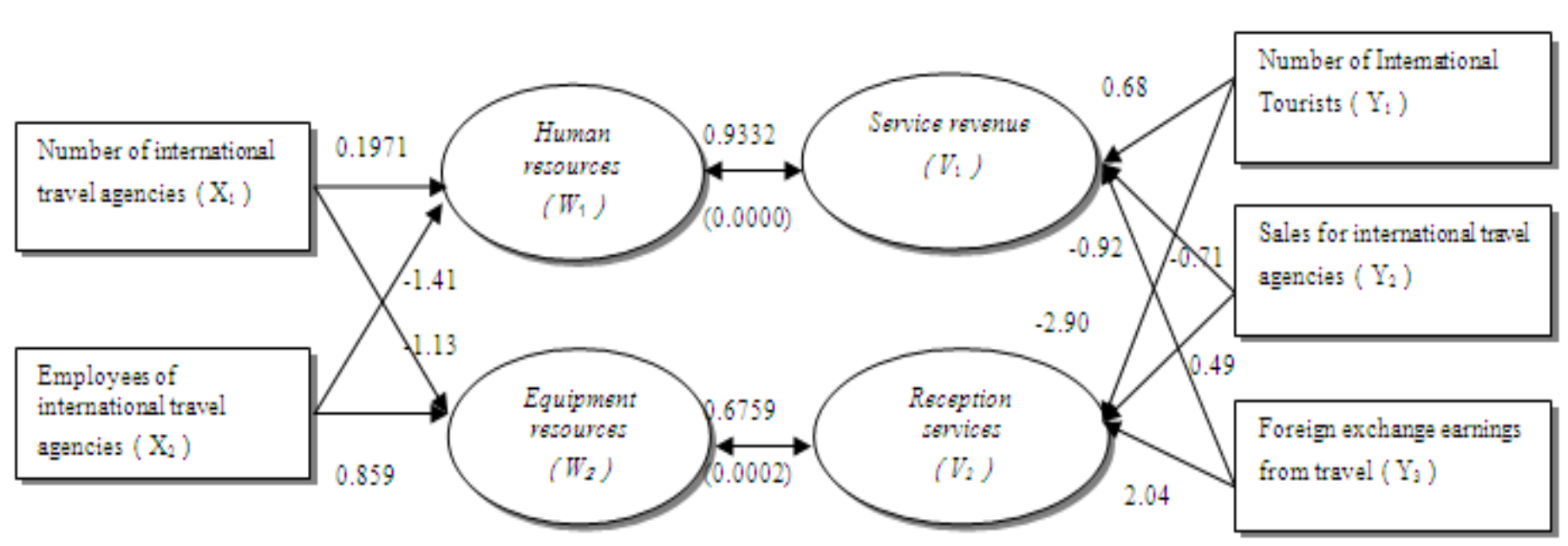

Figure 1. Canonical correlation.

Table 3. Summary statistics and correlation analysis for efficiency measures $(\mathrm{N}=31)$.

\begin{tabular}{lccc}
\hline Variable & CCR & BCC & SBM \\
\hline CCR & 1 & & \\
BCC & $0.73^{\star \star}$ & 1 & 1 \\
SBM & $0.99^{* \star}$ & $0.73^{\star \star}$ & 0.474 \\
Mean & 0.518 & 0.658 & 0.249 \\
S.D & 0.253 & 0.200 & 1 \\
Max. & 1 & 1 & 0.091 \\
Min. & 0.100 & 0.381 & $3(9.67 \%)$ \\
No. of efficient DMUs & $3(9.67 \%)$ & $5(16.12 \%)$ & \\
\hline
\end{tabular}

* Significant at the 0.01 level, ${ }^{* *}$ significant at the 0.05 level, ${ }^{* * *}$ significant at the 0.1 level.

\section{Efficiency analysis}

In this work, the DEA analysis models included CCR, BCC, and the SBM. DEA provides a comprehensive evaluation of overall performance. The results for each DEA model are summarized in Tables 3 and 4. First, an elementary insight is obtained by considering the dichotomous classification of DMUs as either efficient or inefficient. The number of efficient DMUs resulting from the use of different reference technologies is shown in the last row of Table 3 . In addition, Table 3 contains some descriptive statistics for each of the three DEA models and also shows the Pearson correlation coefficients for several of these DEA models, including CCR, BCC, and SBM. The correlation analysis results show a positive relationship among the DEA models investigated in this study.Table 4 presents the CCR efficiency scores under constant returns-to-scale, BCC technical efficiency scores, 
Table 4. Efficiency scores of DEA models for 31 DMUs.

\begin{tabular}{|c|c|c|c|c|c|c|c|c|}
\hline DMU & CCR & $\mathrm{BCC}$ & Scale & SBM & Reference set & Reference frequency & Group & Ranking \\
\hline 1 & 1 & 1 & 1 & 1 & 1 & 14 & 1 & 1 \\
\hline 2 & 0.818 & 0.956 & 0.855 & 0.716 & 9,26 & 0 & II & 5 \\
\hline 3 & 0.728 & 0.768 & 0.947 & 0.626 & 9,26 & 0 & II & 7 \\
\hline 4 & 0.261 & 0.469 & 0.556 & 0.220 & $1,9,26$ & 0 & II & 26 \\
\hline 5 & 0.774 & 0.785 & 0.985 & 0.669 & 9,26 & 0 & II & 6 \\
\hline 6 & 0.556 & 0.597 & 0.931 & 0.478 & 9,26 & 0 & II & 14 \\
\hline 7 & 0.397 & 0.490 & 0.810 & 0.343 & 9,26 & 0 & II & 20 \\
\hline 8 & 0.524 & 0.569 & 0.920 & 0.452 & 9,26 & 0 & II & 16 \\
\hline 9 & 1 & 1 & 1 & 1 & 9 & 27 & I & 1 \\
\hline 10 & 0.726 & 0.749 & 0.969 & 0.721 & 1,9 & 0 & II & 8 \\
\hline 11 & 0.575 & 0.621 & 0.925 & 0.573 & $1,9,26$ & 0 & II & 12 \\
\hline 12 & 0.293 & 0.400 & 0.732 & 0.245 & $1,9,26$ & 0 & II & 23 \\
\hline 13 & 0.621 & 0.695 & 0.893 & 0.580 & 9 & 0 & II & 10 \\
\hline 14 & 0.219 & 0.514 & 0.426 & 0.180 & $1,9,26$ & 0 & II & 29 \\
\hline 15 & 0.551 & 0.571 & 0.964 & 0.475 & 9,26 & 0 & II & 15 \\
\hline 16 & 0.418 & 0.546 & 0.765 & 0.368 & $1,9,26$ & 0 & II & 18 \\
\hline 17 & 0.493 & 0.645 & 0.764 & 0.379 & 9 & 0 & II & 17 \\
\hline 18 & 0.309 & 0.431 & 0.716 & 0.297 & $1,9,26$ & 0 & II & 22 \\
\hline 19 & 0.895 & 1 & 0.895 & 0.764 & 9 & 0 & II & 4 \\
\hline 20 & 0.410 & 0.455 & 0.901 & 0.388 & $1,9,26$ & 0 & II & 19 \\
\hline 21 & 0.289 & 0.410 & 0.704 & 0.277 & 1,9 & 0 & II & 24 \\
\hline 22 & 0.665 & 0.835 & 0.796 & 0.649 & 1,9 & 0 & II & 9 \\
\hline 23 & 0.337 & 0.422 & 0.798 & 0.303 & 9 & 0 & II & 21 \\
\hline 24 & 0.242 & 0.672 & 0.360 & 0.237 & $1,9,26$ & 0 & II & 28 \\
\hline 25 & 0.558 & 0.632 & 0.882 & 0.463 & 9 & 0 & II & 13 \\
\hline 26 & 1 & 1 & 1 & 1 & 26 & 20 & I & 1 \\
\hline 27 & 0.603 & 0.677 & 0.890 & 0.579 & 9,26 & 0 & II & 11 \\
\hline 28 & 0.251 & 0.464 & 0.540 & 0.224 & 9,26 & 0 & II & 27 \\
\hline 29 & 0.100 & 0.661 & 0.151 & 9.13E-02 & $1,9,26$ & 0 & II & 31 \\
\hline 30 & 0.165 & 1 & 0.165 & 0.146 & 1,26 & 0 & II & 30 \\
\hline 31 & 0.287 & 0.381 & 0.753 & 0.242 & $1,9,26$ & 0 & II & 25 \\
\hline
\end{tabular}

"1": Guangdong, "9": Beijing, and "26": Shanghai; "CRS": constant returns-to-scale, "DRS": decreasing returns-to-scale, "IRS": increasing returnsto-scale; "Group I": the host cities or regions of international sporting events, "Group II": other regions.

scale efficiency scores, and slacks-based measure efficiency scores. The main findings can be summarized further. The CCR efficiency score analysis results show that three regions (Beijing, Shanghai, and Guangdong) are relatively efficient based on the same scale efficiency scores and SBM efficiency scores. Their efficiency scores are all equal to 1 . This result shows that resource utilization for these regions were excellent. On the other hand, 28 regions were found to be inefficient because their efficiency scores were less than 1. The scale efficiency scores as defined by the ratio CCR/BCC show large differences between the two groups. The average scale efficiency score was 0.7739 . Of the 31 regions, 21 re-gions have low BCC efficiency scores and relatively high scale efficiency scores, meaning that the inefficiency of these regions as shown in the CCR model is caused by inefficient operations rather than scale inefficiency. Of the 31 regions, two regions have BCC efficiency scores equal to 1 and relatively low scale efficiency scores. This result suggests that the CCR inefficiency scores can be mainly attributed to disadvantageous conditions.

The reference set and their frequencies for the 31 regions are also given in Table 4 . The most frequent reference province was found to be Beijing. The results also show that Beijing, Shanghai, and Guangdong are efficient and are in the reference set of all of the other provinces.

\section{Bilateral analysis}

This work applies the bilateral comparison method to 
Table 5. Bilateral analysis and rank-sum-test.

\begin{tabular}{lcccc}
\hline Group & Number & Average DEA-score & Rank sum & Z-value \\
\hline Group I & 3 & 1.000 & 3 & $-4.611^{*}$ \\
Group II & 28 & 0.466 & 490 & - \\
\hline
\end{tabular}

* Significant at the 0.01 level

international tourism industry to determine the statistical difference in technical efficiency between the host cities or regions of international sporting events (Group I) and other regions (Group II) in the bilateral model.

Thus, Group I comprised three regions, while Group II comprised twenty-eight regions. The rank-sum-test method is used to compare the DEA scores of the two groups. The Rank-Sum-Test (Mann-Whitney) method is a nonparametric test based on the ranking of data. Given independent data belonging to two groups, this method can be used to test the hypothesis that the two groups belong to the same population. In this work, the rank sum for the host cities or regions is 3 , compared to 490 for other regions. Z-values can be used to check the significance of the two groups having different efficiency scores at a given level of significance (a). Table 5 lists the result. The result suggests that host cities or regions of international sport have higher operational efficiency than other regions, indicating that these host cities or regions outperform other regions.

\section{Conclusion}

According to the statistics of World Tourism Organization, China will replace United States and France to become the area of most inbound tourists in 2020. International tourism industry plays the important role in regional economic development. In this work, we have used nonparametric DEA methods to analyze the efficiency of international tourism industry in 31 regions. The main findings can be summarized as follows. First, the canonical correlation analysis revealed a significant correlation between the input and output variables. The CCR efficiency score analysis results show that three regions are relatively efficient, and the results were for scale efficiency and SBM efficiency. Among the 31 regions, three regions exhibit economies of scale, including Beijing, Shanghai, and Guangdong. It infers that those regions have relative efficiency based on these reasons including the time of reform and opening early, high developed economy, a completed value chain of international tourism industry and the unique urban culture. According to the statistics of China Tourism Administration (2007), foreign exchange revenue from travel of those three regions totaled U.S. $\$ 1,795$ billion, accounts for $42.84 \%$ of international tourism industry. Furthermore, the opportunities of holding Olympic Games, international sport games, and World Expositions are beneficial to develop economy of tourism industry. As the hosting location of the 2008 Olympic Games, Beijing is one of the fastest growing regions in China. Meanwhile, Shanghai and Guangdong would hold 2010 World Exposition and 2010 Asian Games to develop economy of tourism industry. Therefore, these regions can effectively develop their tourism industry. The results of bilateral analysis also show that the host cities or regions of international sporting events are superior to other regions in productivity. Thirdly, the inefficient DUMs are mainly attributed to technical inefficiency. Those inefficient host cities and regions need to improve their efficiency through saving costs and enhancing resource usage efficiency with a wider holistic consideration of regional characteristics, economic and tourism planning policies.

Throughout the study, special emphasis has been placed on quantifying and discussing the impact of model choice on the results. For this purpose, a framework for model comparison is introduced and several techniques are used to obtain the results. The results of this research can help those involved in managing these regions understand their relative operating performance and, therefore, respond by appropriately regulating the levels of the input and output variables. Further investigation would be the examination of performance over time to allow a dynamic view of the multidimensional performance of tourism industry.

\section{REFERENCES}

Banker RD, Charnes A, Cooper WW (1984). Some models for estimating technical and scale inefficiencies in Data Envelopment Analysis. Manag. Sci., 30(9): 1078-1092.

Barros CP (2005). Measuring efficiency in the hotel sector. Ann. Tourism Res., 32(2): 456-477.

Barros CP, Alves FP (2004). Productivity in the tourism industry. Int. Adv. Econ. Res., 10(3): 215-225.

Boussofiane A, Dyson RG, Thanassoulis E (1991). Applied data envelopment analysis. Eur. J. Oper. Res., 52(1): 1-15.

Charnes A, Cooper WW, Rhodes E (1978). Measuring the efficiency of decision making units. Euro. J. Oper. Res., 2(1): 95-112.

Chiang W, Tsai $H$, Wang $L$ (2004). A DEA evaluation of Taipei hotels, Ann. Tourism Res., 31(3), 712-715.

Epstein MK, Henderson JC (1989). Data envelopment analysis for managerial control and diagnosis. Decis. Sci., 20(1): 90-119.

Farrell MJ (1957). The measurement of productive efficiency. J. Roy. Stat. Soc. Stat. Soc., 120(3): 253-281.

Haugland SA, Myrtveit I, Nygaard A (2007). Market orientation and performance in the service industry: A data envelopment analysis. J. Bus. Res., 60(11): 1191-1197.

Hsieh LF, Wang LH, Huang YC, Chen A (2010). An efficiency and effectiveness model for international tourist hotels in Taiwan. Serv. Ind. J., 30(13): 2183-2199. 
Huang HC, Chu W, Wang WK (2007). Strategic performance measurement and value drivers: Evidence from the international tourist hotels in an emerging economy. Serv. Ind. J., 27(8): 11111128.

Hwang SN, Chang TY (2003). Using data envelopment analysis to measure hotel managerial efficiency change in Taiwan. Tourism Manag., 24(4): 357-369.

Koksal CD, Aksu AA (2007). Efficiency evaluation of A-group travel agencies with data envelopment analysis (DEA): A case study in the Antalya region, Turkey. Tourism Manag., 28(3): 830-834.

Medina-Borja A, Triantis K (2007). A conceptual framework to evaluate performance of non-profit social service organizations. Int. J. Tech. Manag., 37(1-2): 147-161.

Mota S, Benzecry JH, Qassim RY (1999). A model for the application of data envelopment analysis (DEA) in activity-based management (ABM). Int. J. Tech. Manag., 17(7-8): 861-868.
Parkan C (1996). Measuring the performance of hotel operations. Soc. Econ. Plann. Sci., 30(4): 257-292.

Shang JK, Hung WT, Lo CF, Wang FC (2008). Ecommerce and hotel performance: Three stage DEA analysis. Serv. Ind. J., 28(4), 529540

Tone K (2001). A Slack-based Measure of efficiency in data envelopment analysis. Eur. J. Oper. Res., 130(3): 498-509.

Wang FC, Hung WT, Shang JK (2006). Measuring pure managerial efficiency of international tourist hotels in Taiwan. Serv. Ind. J., 26(1): 59-71.

Yang C, Lu WM (2006). A macro analysis of Taiwan's international tourist hotel industry by using the sliding window method. J. Oper. Res. Soc. Jpn., 49(3): 238-255. 